\title{
Responsabilidad social empresarial y discriminación
}

\author{
WILFREDO ARDITO VEGA*
}

\begin{abstract}
SUMARIO: I. LA DISCRIMINACIÓN EN EL PERÚ.- II. MARCO LEGAL CONTRA LA DISCRIMINACIÓN EN EL PERÚ.- III. RESPONSABILIDAD SOCIAL EMPRESARIAL.- VI. CONCLUSIONES.
\end{abstract}

\section{LA DISCRIMINACIÓN EN EL PERÚ}

Aunque la discriminación está presente en todas las sociedades humanas, en el caso del Perú una serie de características la convierten en un fenómeno mucho más complejo, que ha tornado casi inexistentes las políticas públicas para enfrentarla.

\section{I.1. Un fenómeno negado y natural}

A pesar de su omnipresencia, la discriminación es un problema negado por muchas personas, incluidas autoridades, académicos y hasta sus propias víctimas. Muchas personas, en realidad, sostienen que no son discriminadoras y que en su comportamiento se limitan a tratar de manera diferente a quienes efectivamente son, diferentes. Existe así en el Perú un fenómeno de naturalización de la discriminación; es decir, no parece ser una situación condenable o injusta, sino la simple reacción a diferencias naturales entre las personas.

Una forma en que se produce esta naturalización es mediante el aprendizaje de concepciones racistas desde los años más tempranos: a los blancos se los asocia con mayor capacidad intelectual, mayor atractivo físico, mejor posición económica y don de mando; mientras que indígenas y negros son estigmatizados como peligrosos, poco trabajadores y pobres ${ }^{1}$. Existen también manifestaciones de racismo hacia las personas blancas, pues se asume que son adineradas y arrogantes, pero la discriminación hacia negros y andinos tiene consecuencias mucho más graves, al constituir verdaderas formas de exclusión, sea en el ámbito laboral, en la definición de políticas públicas o en la importancia que se le otorga a la satisfacción de sus necesidades fundamentales.

Aunque resulta innegable la existencia de una gran desigualdad en el Perú, la naturalización permite que no genere mayor cuestionamiento a

* Es abogado por la Pontificia Universidad Católica del Perú y magíster en Derecho Internacional de los Derechos Humanos por la Universidad de Essex. Fundó la Mesa contra el Racismo de la Coordinadora Nacional de Derechos Humanos. Realiza talleres de capacitación sobre la discriminación y promueve acciones de vigilancia ciudadana a nivel nacional.

1 ARDito, Wilfredo. Manual contra la discriminación en la administración pública. Lima: Asociación Pro Derechos Humanos y Oxfam, 2008, p. 9. 
la estructura social o a las relaciones de poder: los mismos pobres tienen la culpa de su propia pobreza. Bastan los rasgos físicos para saber quiénes se encuentran en esta situación.

De esta forma, parece normal que en las zonas rurales, donde existe mayor presencia indígena, el Estado proporcione servicios más deficientes frente a necesidades básicas como salud, educación o justicia²

La discriminación perpetúa la pobreza y aumenta la vulnerabilidad de las víctimas ante abusos laborales, porque se ven excluidas de aquellas actividades donde las condiciones de trabajo con mejores. Igualmente, afecta el crecimiento económico de todo el país y merma la cohesión social y la estabilidad política. Finalmente, afecta la productividad y la competitividad de las empresas, que por motivos discriminatorios dejan de contar con personal adecuadamente capacitado 3 .

\section{I.2. La discriminación acumulada}

A diferencia de otros países, en el Perú el racismo normalmente no aparece solo, sino unido a otros factores de discriminación, como carencias económicas, escasa educación, el apellido, la vestimenta, el lugar de origen o residencia ${ }^{4}$. Igualmente, el machismo se acentúa hacia aquellas mujeres que son pobres, que tienen rasgos indígenas, que provienen de las zonas rurales, que hablan quechua o aimara y que emplean vestimenta tradicional ${ }^{5}$.

Se trata del fenómeno de la discriminación acumulada, que es más diffcil de erradicar que el machismo o el racismo. Un ejemplo evidente de este problema está representado por las trabajadoras del hogar, quienes sufren discriminación por su lugar de procedencia, sus rasgos físicos, su condición económica, su pobreza, su apellido, su situación educativa, su edad y su condición de mujer. Otra situación similar se produce con los campesinos andinos y los indígenas amazónicos ${ }^{6}$.

2 La frecuente práctica de emplear las zonas más pobres como «lugares de castigo» para profesores, policías o médicos que han cometido alguna falta demuestra un total menosprecio por los derechos de la población que habita en dichos lugares.

3 «A mucha gente que veo trabajando en ventas en Estados Unidos jamás les darían una oportunidad en el Perú: son muy gordos, muy viejos o muy negros» (testimonio de una peruana en Nueva York).

4 ARDITO. Óp. cit., p. 18.

5 REID, Claire. "Las múltiples caras de la discriminación en Abancay». Abancay: no publicado, 2007, p. 25. A la inversa, una persona con rasgos andinos pero que al mismo tiempo es de elevada estatura, recibió una buena educación y ostenta una elevada posición económica o ejerce un importante cargo tendrá menos posibilidades de sufrir discriminación. Sin embargo, estos factores deben ser visibles, lo cual implica la exigencia que sienten muchos peruanos andinos, mestizos y negros de invertir mucho en su vestimenta para evitar sufrir discriminación.

6 Otra muestra de discriminación acumulada es la que afecta a los miembros de la religión israelita fundada por Ezequiel Ataucusi: el factor religioso va unido a la vestimenta y a los rasgos físicos andinos de sus integrantes. Los hechos de que los varones no se corten el cabello y de que las mujeres lo tengan cubierto genera muchas dificultades para acceder empleos formales. 


\section{I.3. Discriminación y xenofobia}

En los países europeos, los más discriminados son los extranjeros o quienes tienen apariencia de extranjeros. A nivel laboral, policial o simplemente en la vida cotidiana, son percibidos como amenazantes, peligrosos y como una carga para el Estado de Bienestar. En cambio, en el Perú, las personas hacia quienes suele desarrollarse la discriminación son más bien los peruanos de rasgos autóctonos, pese a ser un grupo mayoritario?

Sufren de discriminación aquellos extranjeros cuyos rasgos físicos los hacen semejantes a los peruanos más discriminados, es decir, los de rasgos andinos y los negros. Ecuatorianos, bolivianos, mexicanos, jamaiquinos o afroestadounidenses han sufrido discriminación en discotecas, hoteles y centros artesanales de nuestro país ${ }^{8}$. Lo mismo ha sucedido con peruanos adoptados cuando eran pequeños por parejas de europeos. Ellos, pese a que cuentan con ciudadanía europea y ni siquiera son hablantes de castellano, son discriminados por sus rasgos físicos.

\subsection{Interiorización de la discriminación}

La discriminación en el Perú se hace más compleja, porque, al haber sido tan marcada durante siglos, ha sido interiorizada por las propias víctimas y es frecuente que una persona de rasgos andinos o africanos actúe de manera discriminatoria hacia alguien similar a él.

No existe todavía en el Perú un movimiento social que promueva asumir de manera positiva los rasgos físicos tradicionalmente discriminados. La noción de belleza sigue asociada a la apariencia más europea?. De esta manera, en la propia sierra el término «serrano» es considerado ofensivo ${ }^{10}$.

La interiorización de la discriminación también se manifiesta en el hecho de que muchas personas de ascendencia indígena busquen eliminar elementos considerados externos para los grupos discriminatorios, como la vestimenta tradicional, el habla pública del quechua o nombres castizos para sus hijos en favor de nombres en inglés.

7 La discriminación hacia afroperuanos es muy particular, pues corresponde a una minoría discriminada por blancos, mestizos y andinos.

8 En junio de 2008, Sixto Murillo, ciudadano ecuatoriano, denunció por delito de discriminación al gerente general de la empresa Perú Rail. Al parecer, su personal pensó que Murillo y su esposa eran peruanos, lo cual implicó que fueran maltratados de manera sistemática en uno de los vagones que normalmente emplean extranjeros. La denuncia fue archivada porque se manifestó que no se podía determinar la relación entre el gerente y los trabajadores de la empresa. Anecdóticamente, debe señalarse que cuando los magistrados acudieron a realizar una inspección también fueron discriminados.

9 El propio presidente Alejandro Toledo declaró varias veces que era «feo", asumiendo que sus rasgos andinos generaban esta apreciación. De otro lado, es marcada la tendencia de mujeres de rasgos andinos o mestizos con cierto éxito a teñirse el cabello de color rubio o castaño.

10 En muchas ciudades andinas, los funcionarios públicos y el personal de las ONG han señalado que no pueden colocar un cartel con la frase «Bienvenidos, serranos» porque la población lo tomaría como una ofensa. Inclusive, la mayoría de habitantes de Arequipa sostiene que esta ciudad se encuentra en la costa.

RESPONSABI-

LIDAD SOCIAL

EMPRESARIAL

Y DISCRIMINACIÓN 
Mientras en otros países suele enfatizarse la necesidad de no discriminar a las personas diferentes, en el Perú es muy fuerte la discriminación hacia el semejante. En el fondo, a muchos discriminados les parece lógico que una persona blanca, peruana o extranjera, merezca un trato cordial o inclusive sumiso.

\subsection{La marcada discriminación indirecta}

La discriminación es directa cuando explícitamente se excluye o desfavorece a determinadas personas por su pertenencia a un grupo. Es abierta e intencional. La discriminación es indirecta cuando estamos ante decisiones aparentemente imparciales y neutras, pero que terminan perjudicando desproporcionadamente a un gran número de personas integrantes de un colectivo determinado. Aunque no pueda comprobarse la intencionalidad, sí puede comprobarse el perjuicio.

Por ejemplo, la falta de adecuación arquitectónica de un edificio no implica la intención de perjudicar a una persona anciana o que padece de alguna discapacidad, pero en la práctica se genera una situación de exclusión ${ }^{11}$.

En el Perú, el mejor ejemplo de esta forma de discriminación es el uso exclusivo del castellano en la administración pública, lo cual impide a la población quechua hablante y a muchos otros ciudadanos el ejercicio de sus derechos.

Otra forma de discriminación indirecta se refiere a la indocumentación. En efecto, en 1996 se dispuso pasar del derecho a obtener una libreta electoral, que era un documento gratuito y permanente, a la obligación de contar con un documento nacional de identidad (DNI), que es costoso y cuenta con una validez de solo ocho años. Esta decisión afectó especialmente a las personas más pobres, muchas de las cuales quedaron indocumentadas o no han podido renovar su $\mathrm{DNI}^{12}$.

La resolución 789-2005-RENIEC emitida en 2005 agravó aun más la situación al prohibir a los funcionarios públicos atender a ciudadanos que carecieran de documento de identidad vigente.

Estas normas afectan de manera indirecta a las mujeres campesinas y nativas, quienes no hablan castellano y habitan en los departamentos más aislados del país. No pueden casarse, ni reconocer a sus hijos, ni entablar una demanda o hacer una denuncia ante un tribunal. Muchas veces, inclusive, se impide el ingreso de las personas sin documentos a las instituciones públicas ${ }^{13}$.

11 Estaríamos ante otro ejemplo cuando una institución coloca determinada información solamente en su portal electrónico, con lo cual resultan discriminadas todas las personas que no cuentan con acceso a Internet.

12 El régimen de la libreta electoral era bastante condescendiente con las limitaciones de la población para obtener documentos. Por ejemplo, los integrantes de las comunidades amazónicas la obtenían en la propia comunidad y, como en ese entonces no existían muchas cámaras fotográficas ni estudios de revelado, el espacio para la fotografía se encontraba en blanco.

13 Entre las instituciones públicas que ponen en marcha esta práctica se encuentran el Congreso de la República, INDECOPI y la mayoría de sedes de los ministerios. 


\section{I.6. Una precisión: la atención preferencial}

El principio de igualdad no implica tratar de igual forma a quienes están en situación de desigualdad. En realidad, este trato aparentemente igualitario generaría consecuencias discriminatorias, como sucede cuando a todos los ciudadanos se les habla en castellano o cuando se establece una misma tarifa para pobres y ricos por un servicio público.

El principio de igualdad implica tratar de manera diferente a quienes se encuentran en una condición diferente, lógica según la cual las personas que se encuentran en una situación más vulnerable requieren más atención. Por ello, se ha establecido que las mujeres embarazadas, los ancianos y las personas con discapacidad requieren una atención más rápida en los establecimientos públicos, mediante la llamada atención preferencial, aprobada por la ley 28683 de marzo de 2005.

La preferencia hacia los más vulnerables no constituye una discriminación hacia el resto de la población, sino una forma de compensar las menores oportunidades de algunas personas.

\section{I.7. Justificación objetiva y razonable}

En algunos casos, se admite realizar diferenciaciones entre individuos por algún motivo que legalmente estaría prohibido, pero no es un caso de discriminación, porque existen justificaciones objetivas o razonables.

El término «objetivo» implica que debe existir claridad en la expresión que plantea la diferenciación. Por ejemplo, expresiones como «buena presencia», «aspecto elegante», «presentación A1» acarrean un carácter sumamente subjetivo. No es posible definir qué es elegante, A1 o buena presencia sin que intervengan apreciaciones individuales y subjetivas, muchas veces racistas.

La expresión «razonable» implica que la diferenciación se origine en una motivación comprensible y lógica de la actividad para la cual se requiere a la persona o en el criterio por el cual a cierto individuo no se le permitió el ingreso a un local.

Por ejemplo, en el ámbito educativo, una razón objetiva que justifica un trato diferenciado puede ser la necesidad de alcanzar un puntaje específico para ingresar a una universidad o un puesto público. También es objetivo y razonable que una empresa solicite que sus practicantes pertenezcan al tercio superior en su año de estudios universitarios o que acrediten determinada experiencia laboral.

El Tribunal Constitucional, en sucesivas sentencias, ha señalado la necesidad de establecer una ponderación de derechos para precisar cuándo se está ante una práctica discriminatoria y cuándo se trata de una diferenciación razonable. 


\section{II.MARCO LEGAL CONTRA LA DISCRIMINACIÓN EN EL PERÚ}

\section{II.1. Discriminación laboral}

La Constitución de 1993, en su artículo 26, señala que uno de los principios de las relaciones laborales es la igualdad de oportunidades sin discriminación. En concordancia, la Ley de Productividad y Competitividad en el Empleo estableció que es nulo el despido cuya motivación sea discriminatoria ${ }^{14}$, así como también que los actos de discriminación son considerados actos de hostilidad equivalentes al despido ${ }^{15}$.

En concordancia con dicha norma, la ley 26772 prohibió la existencia de requisitos discriminatorios en las ofertas de empleo. Esta norma fue modificada por la ley 27270 , que define el concepto de discriminación como: «la anulación o alteración de la igualdad de oportunidades o trato [...] que impliquen un trato diferenciado basado en motivos de raza, sexo, religión, opinión, origen social, condición económica, estado civil, edad o de cualquier otra índole».

El decreto supremo 002-98-TR, que reglamentó la ley 26772, introdujo el concepto de «justificación objetiva y razonable» según el cual determinados requisitos pueden ser tomados en cuenta en una oferta de empleo, si es que se relacionan con las calificaciones necesarias para el desempeño del trabajo concreto (artículo 3). De esta forma, puede admitirse que se exija determinado color de piel a un actor, si es que debe interpretar a un personaje histórico, por ejemplo.

Más recientemente, el decreto supremo 019-2006-TR, reglamento de la ley 28806, Ley General de Inspección de Trabajo, prohibió las conductas discriminatorias en toda la relación laboral, al señalar que constituyen una «infracción muy grave». Se especifica que la contratación, la retribución, la jornada, la formación y demás condiciones laborales no pueden tener carácter discriminatorio. Se sanciona tanto la discriminación directa como la indirecta, aunque no esté probada la intención de discriminar, pero sí las consecuencias desproporcionadas sobre un grupo social (artículo 25.17).

Finalmente, el Convenio 111 de la OIT establece que las distinciones, exclusiones o preferencias basadas en las calificaciones exigidas para un empleo determinado no serán consideradas como discriminación (artículo 1.2). Es decir, resulta comprensible exigir inglés para un empleado que va a atender turistas o pedir fortaleza física para determinados trabajos que lo requieran. Sin embargo, sería subjetivo, y por lo tanto discriminatorio, otorgar mayor porcentaje a quienes han estudiado en determinadas universidades.

14 Artículo 29, letra a, según el Texto Único Ordenado que aparece en el decreto supremo 003-TR-97, del 21 de marzo de 1997.

15 Artículo 30 , literal f. 


\section{II.2. Discriminación a los consumidores}

En 1998, fue aprobada la ley 27049, que realizó dos importantes modificaciones al decreto legislativo 716, Ley de Protección al Consumidor. En primer lugar, precisó que el inciso d) del artículo 5 del mencionado decreto, al referirse a la protección de los intereses económicos de los consumidores, implica que estos no pueden ser discriminados por motivos de raza, sexo, nivel socioeconómico, idioma, discapacidad, preferencias políticas, creencias religiosas o de cualquier otra índole en la adquisición de productos y prestación de servicios que se ofrecen al público. En segundo lugar, se incorporó al decreto legislativo 716 el artículo 7-B, que dispone la prohibición expresa de cualquier discriminación o selección de clientela.

Al reglamentar la norma, el decreto supremo 02-1998-TR admite, sin embargo, la posibilidad de que, por razones objetivas o justificadas, el proveedor de un servicio impida el ingreso de una persona a su local comercial o se niegue a proporcionarle el servicio ofrecido. Entre las razones objetivas o justificadas, se considera la seguridad del establecimiento o la tranquilidad de los demás clientes. De esta forma, no será discriminación impedir el ingreso a una persona ebria, drogada o armada. También sería considerado una razón objetiva reservar un espectáculo a mayores de edad. Los funcionarios de INDECOPI sostienen que se puede establecer, por razones objetivas, un código de vestimenta, sin que ello sea discriminatorio.

La ley 27049 dispuso que la carga de la prueba corresponde a la persona discriminada, lo cual hace muy difícil la sanción, por cuanto normalmente la discriminación se produce de manera inesperada, sin que la víctima tenga los mecanismos para registrarla. Debe señalarse, además, que los denunciantes deben pagar una tasa, lo cual representa un fuerte elemento disuasivo. A esto se añade el hecho que INDECOPI no brinde asesoría a las víctimas, pese a que pueden sufrir represalias o presiones por parte de los discriminadores.

Algunos funcionarios de INDECOPI parecen creer que su función es tomar distancia y conducirse con una aparente neutralidad, como si percibieran al denunciante con desconfianza. En algunas ciudades, los propios funcionarios pueden pertenecer al círculo social que acude a los locales discriminadores, hecho que bloquea su intervención ${ }^{16}$.

Finalmente, es también disuasivo el hecho de que, si se produce una sanción pecuniaria, esta se destina a INDECOPI y no a la víctima. Para obtener una reparación civil, la víctima de discriminación debe a iniciar un nuevo proceso, esta vez por la vía judicial, con resultados inciertos. 
A pesar de todas estas dificultades, desde el año 2004 varios comercios de Cusco y Lima han sido severamente sancionados por INDECOPI con multas o inclusive con la clausura del local ${ }^{17}$. Aun así la práctica persiste, especialmente en Cusco $^{18}$.

\subsection{Tratamiento penal de la discriminación}

La ley 27270, aprobada en 2000, tipificó el delito de discriminación y lo incorporó al artículo 323 del Código Penal; sin embargo, no lo definía, lo que hacía muy difícil su aplicación. Señalaba solamente cuatro causales: diferencia racial, étnica, religiosa y sexual. Las penas eran también sumamente benévolas: entre treinta y sesenta días de servicio comunitario.

La ley 28867, promulgada en 2007, modificó el artículo 323 del Código Penal; definió «discriminación» como la acción realizada con el objeto de anular o menoscabar el reconocimiento, goce o ejercicio de los derechos de la persona. Se señala, además, que el delito puede cometerse de manera directa o mediante terceras personas, como sucede en determinados establecimientos en que los porteros o vigilantes reciben órdenes de impedir el ingreso de personas de rasgos andinos o afroperuanos.

Este nuevo artículo 323 presenta una lista más amplia de causales penadas de discriminación: filiación, identidad étnica y cultural, idioma, indumentaria, opinión política o de cualquier otra índole, edad y discapacidad.

Establece sanciones más severas, incluso penas privativas de la libertad de dos a tres años, que pueden extenderse a cuatro cuando se trate de un funcionario público o cuando se haya empleado violencia.

\section{I.4. Dificultades para el cumplimiento de la normatividad}

Pese a que algunas de las leyes mencionadas tienen más de diez años de vigencia, su cumplimiento hasta el momento ha sido limitado debido a una serie de factores:

a. Escasa difusión. La mayoría de ciudadanos ignora que estas normas existen; lo mismo ocurre con los propios funcionarios estatales encargados de hacerlas cumplir. Las personas que reconocen que la discriminación existe todavía la consideran solo un acto negativo o moralmente reprobable, pero no una infracción legal.

b. Dificultades de fiscalización. Las normas que protegen a los consumidores de la discriminación deben ser cumplidas por INDECOPI, con oficinas solamente en diez ciudades del país. Igualmente, el 
Ministerio de Trabajo cuenta con muy pocos inspectores para intervenir en prácticas discriminatorias.

c. Ausencia de voluntad política. En muchos casos, como las ofertas de empleo, las infracciones a las normas son evidentes, pero no ha habido mayor intervención ni del Ministerio Público ni del Ministerio de Trabajo. Muchos funcionarios públicos consideran que, al ser la discriminación parte del orden natural de las cosas, carece de sentido intervenir para corregirla.

d. Dificultades burocráticas. Las instituciones públicas en el Perú establecen numerosos requisitos que en la práctica hacen muy difícil que los ciudadanos presenten sus denuncias. INDECOPI y el Ministerio de Trabajo inclusive impiden el ingreso a todos los ciudadanos que no lleven consigo su DNI.

e. Dificultades personales para los denunciantes. La discriminación es una experiencia muy dolorosa y la denuncia implica volver a vivirla. Por ello, la mayoría de víctimas de discriminación prefiere negar u olvidar lo sucedido.

f. Ausencia de asesoría. Las instituciones que legalmente enfrentan la discriminación no cuentan con personal que apoye a las víctimas. En el Poder Judicial o el Ministerio Público, el personal que debería atenderlas reproduce las prácticas discriminatorias. Una situación similar se produce en INDECOPI o, inclusive, en algunos casos, en la Defensoría del Pueblo.

En aquellas instituciones a cargo de la administración de justicia y la seguridad, como el Poder Judicial, el Ministerio Público y la Policía Nacional, no existen políticas o lineamientos para enfrentar la discriminación. La actitud de los integrantes de estas instituciones respecto de los ciudadanos depende mucho de su ubicación social, de sus rasgos físicos, de su apellido o de su vestimenta. Inclusive, en casos muy graves como homicidio o violación, la respuesta estatal será muy débil si la víctima pertenece a los sectores discriminados ${ }^{19}$.

Todo este panorama muestra la necesidad de que el problema de la discriminación sea abordado por instancias mucho más cercanas a los ciudadanos, como gobiernos municipales, provinciales, distritales y regionales. 


\section{I.5. Ordenanzas contra la discriminación}

Durante los últimos tres años, más de cincuenta municipalidades provinciales y distritales y cinco gobiernos regionales han aprobado ordenanzas en contra de la discriminación. La mayoría de estas normas disponen la revocatoria de la licencia de funcionamiento de los locales que pongan en marcha prácticas discriminatorias. Sin embargo, las ordenanzas más recientes plantean, adicionalmente, la prohibición de avisos con requisitos discriminatorios y exigen carteles que señalen la prohibición de discriminar en el distrito o en la provincia en cuestión.

Los gobiernos regionales de Apurímac, Ayacucho, Huancavelica y Junín también han dispuesto, de manera muy avanzada, una serie de medidas para prevenir la discriminación en el ámbito laboral, educativo y de salud, y se encuentran en proceso de transformarlas en políticas públicas.

A diferencia de las leyes mencionadas, las ordenanzas contra la discriminación han tenido una amplia difusión a nivel local, lo cual ha contribuido a disuadir a muchas personas de continuar practicando actos discriminatorios. Las organizaciones locales vienen promoviendo el seguimiento de estas normas. El relativo éxito de las ordenanzas hace evidente la necesidad de una política a nivel nacional.

\section{Responsabilidad social empresarial}

La discriminación no solamente debe ser enfrentada por instituciones estatales sino también por el propio ámbito empresarial. La actividad de cualquier empresa está presente, de manera explícita o implícita, en las relaciones entre los empleados y también frente al público.

Su existencia desde un punto de vista meramente económico se traduce en problemas como la desmotivación de los trabajadores para desarrollarse en su carrera ${ }^{20}$ o en una institución. De otro lado, la discriminación también desmotiva a los propios beneficiados: sienten que no tienen que obtener notas altas o seguir cursos de especialización porque siempre tienen más posibilidades de ser contratados.

De esta manera, los prejuicios terminan afectando el desarrollo empresarial en sí mismo. Una práctica tan extendida como el racismo empobrece al propio centro laboral, que se priva de o que subvalora a personal calificado.

Todas las instituciones públicas y las empresas privadas deberían contar con un plan para enfrentar la discriminación. En este, es fundamental incluir a todo el personal, desde vigilantes hasta gerentes. A continuación, presentamos algunas de las áreas más sensibles sobre las que

20 «Si no eres alto y [no] tienes apellido italiano o alemán, es imposible ascender en esa empresa» (testimonio de un ingeniero respecto a una compañía de seguros). "Con mi apellido, Quispe, por más [de] que estudie y me capacite, nunca me llamarán de un banco importante» (testimonio de una secretaria de rasgos andinos). 
debería prestarse atención. Una intervención oportuna puede prevenir muchos conflictos.

\section{1. Políticas de contratación}

RESPONSABI-

No solo por el cumplimiento de la ley, o por temor a una sanción, es fundamental evitar que las ofertas de empleo tengan algún requisito subjetivo o discriminatorio. La selección de empleados por criterios subjetivos y discriminatorios puede conllevar consecuencias negativas para la propia empresa ${ }^{21}$.

De otro lado, en la actualidad, además, existe mayor conciencia en la población. Una empresa con un aviso discriminatorio puede ser denunciada, sea por los afectados, por alguna ONG de derechos humanos o por la Defensoría del Pueblo ${ }^{22}$. Por todo ello, es fundamental que el personal administrativo maneje la legislación sobre ofertas de empleo para evitar requisitos prohibidos.

Hasta el momento, el requisito ilegal más frecuente se refiere a la edad, pero también aparecen ofertas de empleo con restricciones en cuanto a sexo, estado civil o universidad de origen.

Aunque la expresión «buena presencia» no tiene un carácter racial explícito, se trata del eufemismo comúnmente usado en nuestro medio para recalcar que los rasgos físicos serán tomados en cuenta. Por ello, es necesario evitarla, aun en aquellas jurisdicciones donde todavía no ha sido taxativamente prohibida ${ }^{23}$. Lo mismo se reza para frases como «excelente presentación personal» o «apariencia A1». De igual manera, deben omitirse requisitos que podrían generar la impresión de que se producirá una selección discriminatoria, como la exigencia de una fotografía ${ }^{24}$.

También debe evitarse la discriminación durante el proceso de contratación. Para ello, es necesario que las empresas consideren como un valor positivo la pluralidad a nivel de rasgos físicos, experiencias personales y lugar de origen ${ }^{25}$. El personal a cargo de la selección debe evitar manejar conceptos subjetivos basados en los rasgos físicos de la persona, en su edad, en su lugar de residencia o en su apellido. En algunos casos, será

21 Hace pocos años, una importante empresa de telecomunicaciones comprobó que sus empleados blancos tenían muchas dificultades para tratar adecuadamente a clientes mestizos y andinos, lo que generaba dificultades en las ventas y bajos índices de satisfacción en sus clientes.

22 En las últimas semanas, algunas ONG y universidades fueron muy criticadas por haber incluido requisitos de edad en sus ofertas de empleo. El rechazo fue tan fuerte que tuvieron que eliminar los requisitos.

23 Hasta el momento, esta expresión ha sido prohibida por las ordenanzas municipales de Miraflores, Jesús María, Lince y Callao, así como por las ordenanzas regionales de Junín, Huancavelica, Ayacucho y Apurímac.

$24 \mathrm{La}$ exigencia de una fotografía ha sido prohibida por las ordenanzas regionales mencionadas en la nota anterior y por las ordenanzas distritales de Belén (Iquitos) y Lince (Lima).

25 «En el fondo, en mi estudio no desean pluralidad. Por eso para ellos solo los egresados de dos universidades pueden ingresar como socios» (testimonio de un abogado). 
necesario precisar que el «perfil» de un puesto no debe obedecer a estos criterios.

En cuanto a la justificación de que el público desea ver a una persona joven o blanca, el artículo 4 del decreto supremo 002-98-TR es claro al señalar que la supuesta preferencia de los clientes no es una causal objetiva que pueda permitir la discriminación ${ }^{26}$.

El mismo artículo indica que los costos mayores que podría implicar la contratación de una persona no suponen una razón objetiva (esta precisión se basa en que contratar a una persona con discapacidad o a una mujer que pueda quedar embarazada puede generar algunos costos extras para la empresa). Tampoco se admite discriminar a una persona por su pertenencia a un gremio o asociación con fines lícitos. En esta categoría se encuentran desde los sindicatos hasta las agrupaciones políticas.

A muchas empresas les ayudaría plantear políticas de discriminación positiva para generar espacios más plurales. Hasta el momento, solo algunos establecimientos — como la cadena de supermercados Wongpractican esta política en relación con personas con discapacidad.

Finalmente, para la contratación del personal en las zonas donde el quechua o el aimara son predominantes, sería fundamental tomar en cuenta el manejo del idioma respectivo. En la actualidad, esto es obligatorio en las entidades públicas de algunas provincias y regiones, pero también deberían asumirlo las empresas privadas, por su propia responsabilidad.

\section{III.2. Atención al público}

La atención al público representa un ámbito en el cual es fundamental evitar prácticas discriminatorias. Normalmente, la capacitación que se brinda a los empleados a cargo de esta tarea no toma en cuenta los prejuicios existentes en la sociedad, que han sido aprendidos por ellos durante su socialización. Algunos empleados pueden pensar que no vale la pena atender con esmero a las personas que tienen pocos recursos económicos; para deducirlo, se basan en elementos externos como apellido, talla, vestimenta y color de piel $^{27}$.

Para enfrentarlos, resulta fundamental que este personal sea consciente de sus propios prejuicios. Es posible que exista un perfil inconsciente o consciente sobre el usuario y que quien no corresponde con este sea maltratado ${ }^{28}$. Existe especial necesidad de ayudar a vencer sus prejuicios al personal que actúa en negocios dirigidos a sectores altos y medios,

26 Algunas instituciones educativas argumentaban que este era el criterio por el que imponían un límite de edad a tutores o profesores.

27 Determinados peinados, tintes de pelo, gorras, anteojos o aretes pueden ser asociados a determinada condición socioeconómica.

28 Por ejemplo, aunque ciertos supermercados se caracterizan por la cordialidad hacia el público, varias personas de rasgos andinos se han quejado de no ser bien tratadas. Las quejas de las trabajadoras del hogar también son recurrentes. 
porque es en ellos que han sido frecuentes los maltratos por motivos raciales $^{29}$.

Una regla muy simple, como evitar el tuteo a las personas desconocidas, sería muy útili ${ }^{30}$. En otros casos, podrían colocarse en lugares públicos carteles con frases como «En esta oficina no se discrimina» o disponerse buzones para quejas del público.

Otra tarea pendiente puede ser la adecuación arquitectónica para evitar la discriminación hacia personas con discapacidad. Se debe también promover que, en aquellas regiones donde el quechua o el aimara sean predominantes, existan siempre empleados hablantes de estos idiomas ${ }^{31}$.

La peor manifestación de discriminación en la atención al público, naturalmente, es impedir el ingreso de una persona a un establecimiento. Recordemos que esta decisión solo se puede tomar debido a un criterio objetivo o razonable ${ }^{32}$.

Sería en cambio discriminatorio establecer criterios no razonables, como sucede cuando en una entidad no se permite ingresar al público que viste de manera informal o a la indígena, o que usa el cabello largo. Igualmente, no es razonable que en instituciones públicas se impida el ingreso a las personas que no portan su DNI, mientras que tienda, banco o empresa privada alguna maneja estos criterios.

Es subjetiva también la exigencia de vestir de manera «elegante» para ingresar a algunos establecimientos. $\mathrm{Al}$ respecto, mientras el decreto legislativo 716 no hace mayores menciones al respecto, las ordenanzas contra la discriminación explicitan que no puede haber restricciones basadas en la indumentaria de las personas.

Para evitar posibles malas interpretaciones, es conveniente que los locales expongan de manera visible y precisa las posibles restricciones existentes y que eviten expresiones ambiguas como «Nos reservamos el derecho de admisión», lo cual no está permitido según INDECOPI y que, además, la mayoría de ordenanzas han prohibido expresamente.

En los casos en que la seguridad es ofrecida por una empresa externa, esta debe garantizar que su personal haya sido capacitado para evitar prácticas discriminatorias. Especial atención merecen aquellas entidades como organismos internacionales cuya preocupación por la seguridad lleva a situaciones desagradables, desde decomisar documentos

29 «Pese a que tengo la tarjeta preferente del Banco de Crédito, normalmente me tratan mal porque creen que soy el mensajero de algún local» (testimonio de un cliente de rasgos andinos). "Tenía en la mano las entradas para la zona VIP de un concierto y el vigilante, que era como yo, no me quería dejar pasar» (testimonio de un empresario afroperuano).

30 En este caso, habrá que tener cuidado con el racismo inconsciente, por el que muchas personas creen que es imposible tratar de «usted» a quien consideran inferior.

31 En los aviones de la aerolínea LC Busre que vuelan hacia Ayacucho, todas las instrucciones de seguridad se encuentran escritas en castellano, quechua e inglés.

32 Artículo 7-B del decreto legislativo 716, incorporado por la ley 27049.

RESPONSABI-

LIDAD SOCIAL EMPRESARIAL Y DISCRIMINACIÓN 
de identidad y celulares a los invitados, hasta inclusive pedir que se desinfecten antes de ingresar a un establecimiento ${ }^{33}$. Con frecuencia, el personal peruano que trabaja en estas entidades expresa prejuicios discriminatorios hacia sus compatriotas, pero estos problemas también pueden manifestarse en personal extranjero ${ }^{34}$.

\section{III.3. Políticas internas}

La mayor parte de la actividad de una empresa se desarrolla hacia adentro y, por ello mismo, resulta fundamental prevenir la discriminación en las relaciones entre los propios empleados y trabajadores.

Nuestro punto de partida debe ser aceptar que la discriminación existe y que puede manifestarse de manera distinta en cada empresa: hacia los trabajadores administrativos, hacia los obreros, hacia los choferes. Es posible que una estructura organizacional genere discriminación al otorgar más ventajas para los integrantes de una determinada área o a quienes llevan a cabo cierta función. Cuando más grande es la empresa, más peligro de situaciones de discriminación entre áreas existe.

De igual forma, es factible que la condición laboral marque un trato discriminatorio, como suele ocurrir para los trabajadores que tienen menos estabilidad o que se encuentran afiliados a un sindicato.

Por todo ello, es fundamental organizar charlas y talleres en el centro laboral acerca de los prejuicios y estereotipos raciales existentes en nuestra sociedad. Si la actividad se realiza de manera participativa y se logra una atmósfera horizontal, los resultados pueden ser sorprendentes ${ }^{35}$.

Es importante, luego de haber identificado las causales predominantes de discriminación, aprobar normas internas — como reglamentos- que establezcan procedimientos para que las prácticas discriminatorias puedan ser denunciadas y sancionadas.

En dichas normas, es conveniente señalar que las bromas discriminatorias se encuentran prohibidas, pues es muy común que, mediante estas, los prejuicios y estereotipos se expresen abiertamente. Un buen clima laboral no puede disfrazarse de un falso ambiente informal si allí se registran situaciones como estas. En algunos lugares, esto implicará enfrentar prácticas culturales que permiten burlarse de las personas de condición social inferior ${ }^{36}$. empleados «para así conocerlos mejor».

35 Muchas personas pueden experimentar formas de discriminación, pero no suelen señalarlas o denunciarlas porque creen que se trata de situaciones normales. Un taller o una actividad corporativa sobre el tema pueden posibilitar conocer mejor estos problemas.

36 «En ventas es así», señala el trabajador de una empresa cervecera al referirse a las bromas sobre rasgos físicos u orientación sexual que a veces exasperan a algunos vendedores. 
De manera complementaria, es conveniente colocar también carteles en lugares visibles donde se señale la condena a la discriminación, las sanciones legales y las que establecerá la propia empresa ${ }^{37}$.

Puede ser importante prestar atención a diferencias religiosas o a criterios particulares que puedan generar dificultades endémicas: por ejemplo, ofrecer carne durante un almuerzo institucional sin tomar en cuenta que algunos trabajadores no pueden ingerirla.

Si bien las jerarquías laborales son importantes para la correcta marcha de toda institución, se está ante un problema serio cuando estas no coinciden con las jerarquías sociales ${ }^{38}$.

De otro lado, es importante reflexionar si algunas prácticas, como establecer vestimentas diferentes, designar ambientes separados para comer o emplear títulos profesionales y cargos, obedecen a una verdadera necesidad laboral o si más bien pueden generar o reforzar situaciones de discriminación.

Merecen atención especial aquellas formas de discriminación indirecta que impliquen perjudicar a un sector de trabajadores. En muchas $\mathrm{ONG}$, por ejemplo, pese a su compromiso con un trato equitativo, es marcada la diferencia de las condiciones de sus empleados entre la sede de Lima y las del interior del país ${ }^{39}$.

Finalmente, también es especialmente importante tener cuidado en las actividades de integración, durante las cuales puede generarse una situación de hostilidad o de aislamiento hacia quienes tienen diferentes formas de pensar, por motivos religiosos o culturales ${ }^{40}$. Fomentar un trato igualitario para todos puede representar una excelente vía para poner en evidencia con más claridad situaciones de desigualdad ${ }^{41}$.

\section{III.4. Publicidad}

En el Perú todavía no existe una regulación en materia de publicidad para evitar criterios discriminatorios, pese a que la publicidad peruana reproduce y refuerza marcados estereotipos discriminatorios: personas

37 Estas sanciones deben ser aplicadas si se llegan a producir los hechos, pues de lo contrario se pierde el respeto hacia la norma.

38 Por ejemplo, una secretaria de rasgos blancos o limeña puede sentir menosprecio hacia un superior de rasgos andinos, sea provinciano, mujer o más joven que ella. En este caso, una actitud frecuente es que el superior busque afianzar su autoridad. Sería sumamente peligroso que el principio de autoridad se quebrara y una jerarquía social se viera fortalecida.

39 En algunas ONG ni siquiera se asigna papel higiénico para los baños de las oficinas de provincias. Con frecuencia, las posibilidades de mayor formación o capacitación se restringen a los empleados que están en Lima.

40 Por ejemplo, disponer que todo el personal participe en una actividad religiosa puede atentar en contra de la libertad de quienes no comparten dichas ideas. Algunas personas no podrán participar en una actividad durante el sábado o el domingo. Una celebración por el Día del Trabajo que excluya a los empleados contratados o los trabajadores de los services profundizaría las tensiones laborales.

41 En una ONG, se dispuso que todos los trabajadores debían participar en la actividad del «amigo secreto" (intercambio de regalos) con un monto mínimo adecuado para directores pero notablemente elevado para personal que ganaba el sueldo mínimo.

RESPONSABILIDAD SOCIAL EMPRESARIAL Y DISCRIMINACIÓN 
blancas son asociadas con el éxito, la prosperidad y la felicidad familiar, mientras que andinos y negros son mostrados como exóticos, violentos o marginales.

Es cierto que a algunas personas ese tipo de publicidad les parece «normal», ello porque han interiorizado patrones de belleza que se desplazan en este sentido. Sin embargo, las consecuencias son muy graves en cuanto a la autoestima colectiva. Muchas personas creen que no son atractivas solo porque quienes comparten sus rasgos aparecen en roles subordinados en los medios de comunicación. Para niños y adolescentes, la situación es mucho más grave ${ }^{42}$.

Resulta fundamental, por ello, pasar de la publicidad aspiracional a la publicidad de reconocimiento. En los últimos años se han registrado algunos avances - por ejemplo, la inclusión de la actriz andina Magaly Solier en la publicidad de Saga Falabella-, pero aún prima una mentalidad conservadora en esta materia ${ }^{43}$.

Es necesario que las empresas reflejen la diversidad étnica existente entre los consumidores peruanos y que aprendan a romper estereotipos. Especialmente, se debe prestar especial atención a toda la publicidad referida a niños y a felicidad familiar, en la cual la carga racista es mucho más fuerte (publicidades por el Día de la Madre o del Padre, por Navidad, etcétera). Las empresas que busquen dotarse de una imagen de estatus pueden hacerlo mediante campañas más creativas.

Finalmente, la publicidad podría emplear mejor los diferentes idiomas que se hablan en el Perú, de manera que se posicione la identidad regional y se recupere el aprecio hacia ellos ${ }^{44}$. Un anuncio en quechua de Inca Kola en Cusco o un aviso del Banco de Crédito en shipibo en Ucayali tendrían mucho éxito ${ }^{45}$.

\section{III.5. Políticas en relación con los proveedores}

Las empresas deben prestar especial cuidado a que los services que contratan no lleven a cabo prácticas discriminatorias hacia vigilantes, mensajeros o trabajadores de limpieza. A veces se puede convivir con situaciones de injusticia, como por ejemplo demoras en los pagos, abusos o maltratos, y condiciones laborales muy duras. Por ello, se debe asegurar

42 El publicista Gustavo Rodríguez y el psicoanalista Jorge Bruce han señalado en reiteradas oportunidades que la publicidad racista en el Perú genera en las personas una contaminación tan grave como la contaminación ambiental.

43 El año pasado, el Grupo Interbank inauguró su primera tienda Oeschle en Huancayo y adoptó como símbolo a la actriz Roxana Fernández Maldonado, físicamente muy distinta de los consumidores huancaínos. Interbank ha mantenido a dicha actriz como imagen para publicitar su tienda del Centro Cívico, donde se aprecia la misma disonancia con el público.

44 Gracias a una sugerencia nuestra, la empresa Claro empleó quechua, aimara, ese eja y otros idiomas amazónicos en su publicidad, pero los participantes nunca usaban teléfonos celulares, por lo cual se mantuvo una visión más bien exótica de la vida rural.

45 Sin embargo, en Lima las agencias bancarias de la calle Capón emplean avisos en chino. 
el cumplimiento de los derechos laborales como exigencia para contratar a un determinado service.

Igualmente, todos los trabajadores de la empresa deben tener especial cuidado en evitar maltratar a dicho personal, pero al mismo tiempo el personal de los services debe ser capacitado para evitar prácticas discriminatorias.

En relación con los trabajadores que laboran bajo la modalidad de giro de recibos por honorarios o como contratados, aunque formalmente no son parte de la institución, en la práctica suelen encontrarse allí de manera permanente y con frecuencia pueden ser objeto de discriminación, pues la inseguridad en que se encuentran hace que difícilmente puedan reclamar sus derechos, aun aquellos más conocidos que dispone la ley.

Resulta muy conveniente promover también en todos los empleados el reconocimiento de su posible condición de empleadores. Difundir el contenido de las normas sobre derechos de las trabajadoras del hogar (vacaciones, gratificación, CTS) y estimular su cumplimiento resulta una tarea que pocas empresas han tomado en cuenta. Hasta el momento, solamente algunas embajadas han planteado esta situación para su personal, tanto extranjero como peruano. Debemos señalar que muchas personas pueden conocer más a una empresa por intermedio de la conducta cotidiana de sus empleados.

\section{III.6. Manejo de denuncias}

Si bien hasta hace unos años muy pocas personas sabían que la discriminación constituía una práctica ilegal, actualmente existe cada vez mayor conciencia al respecto. Normalmente, las personas que más denuncian estos hechos son aquellas que conocen perfectamente la situación por las que han sido discriminadas, entre ellas, personas con discapacidad y víctimas de discriminación por edad.

Las víctimas de racismo normalmente prefieren no denunciar, pues ello implica admitir que sus rasgos las hacen pasibles de sufrir discriminación, lo cual, en realidad, es doloroso. Por eso, muchas denuncias de esta clase son presentadas por familiares o amigos de la víctima. Sin embargo, cada vez más personas enfrentan y denuncian este problema. Tratándose de una situación tan delicada, es importante afrontar el tema con el debido respeto.

Ante una denuncia, es importante mantener la calma y reconocer que es altamente probable que sí se haya producido una conducta discriminatoria. Es preferible permitir que la persona pueda exponer lo que ocurrió, pedir disculpas y anunciar una investigación al respecto.

Para muchas personas, esto puede ser suficiente. Sin embargo, algún tipo de gesto puede ser útil, siempre que parta del propio empleado responsable. Es también normal que el empleado involucrado niegue lo ocurrido,

RESPONSABILIDAD SOCIAL EMPRESARIAL Y DISCRIMINACIÓN 
sea porque no fue consciente de sus actos, porque se dejó llevar por un prejuicio que después superó o porque no quiere ser sancionado. De acuerdo a la gravedad de los hechos, se puede optar por una sanción o por una recomendación para que no se repitan estas situaciones.

Sería un error también percibir el incidente como una situación aislada y considerar, por ejemplo, que en la empresa existe «un» empleado racista. Más bien, el incidente debe ser percibido como una oportunidad para abordar esta problemática.

\section{CONCLUSIONES}

En los últimos años, el Estado peruano ha promulgado diversas normas para enfrentar la discriminación en el ámbito laboral y empresarial, pero muchas de ellas no han sido adecuadamente difundidas ni se han dado los pasos necesarios para su implementación.

Esta situación no debe impedir a las propias empresas llevar a cabo políticas internas para aplicar las normas y enfrentar este problema. Un ambiente laboral libre de discriminación logrará una mejor atmósfera de trabajo y relaciones más positivas entre los trabajadores de la empresa e incluso con el público. En poco tiempo, será fácil concebir los resultados. 